PEDAGOGIA : Jurnal Ilmu Pendidikan

\title{
KECENDERUNGAN PERILAKU CYBERBULLYING PADA PESERTA DIDIK BERDASARKAN JENIS KELAMIN
}

\author{
Ipah Saripah \\ Ajeng Nurul Pratita \\ Departemen Psikologi Pendidikan dan Bimbingan \\ Fakultas Ilmu Pendidikan \\ Universitas Pendidikan Indonesia \\ ipah_bk@upi.edu
}

\begin{abstract}
Abstrak
Kemudahan dalam memanfaatkan teknologi serta bergesernya pola komunikasi dari tatap muka ke online menjadikan remaja sebagai salah satu komunitas yang paling rentan terkena dampak negatif teknologi. Salah satu dampak negatif teknologi dan komunikasi online adalah munculnya perilaku cyberbullying di kalangan peserta didik. Terdapat penyikapan serta intensitas yang berbeda antara remaja laki-laki dan perempuan dalam peristiwa cyberbullying. Penelitian bertujuan menyajikan data empirik mengenai kecenderungan perilaku cyberbullying berdasarkan jenis kelamin yang dilakukan peserta didik Kelas VIII di salah satu SMP di Kota Bandung Tahun Ajaran 2017/2018. Pendekatan penelitian yang digunakan adalah kuantitatif dengan metode penelitian deskriptif dan desain penelitian survei. Hasil penelitian menunjukkan: 1) kecenderungan perilaku cyberbullying peserta didik Kelas VIII berada pada intensitas rendah sekali baik secara keseluruhan maupun berdasarkan bentuk; 2) kecenderungan perilaku cyberbullying berdasarkan jenis kelamin pada peserta didik Kelas VIII berada pada intensitas rendah sekali pada setiap bentuk yang ada, namun terdapat dua bentuk perilaku yang memiliki intensitas tinggi yakni cyberstalking (menguntit/mengikuti) dan exclusion (mengeluarkan).
\end{abstract}

Kata Kunci: Cyberbullying; Jenis Kelamin; Peserta Didik

\begin{abstract}
The ease of utilizing technology and the shifting pattern of communication from face to face to online make adolescents one of the most vulnerable communities to the negative impact of technology. One of the negative effects of technology and online communication is the emergence of cyberbullying behavior among teenagers. There is a different attitude and intensity between boys and girls in cyberbullying events. The study aimed to produce empirical data regarding the tendency of cyberbullying behavior based on gender by Class VIII students in one of the junior high schools in Bandung City Academic Year 2017/2018. The research approach used is quantitative with descriptive research methods and survey research designs. The results of the study show: 1) the tendency of cyberbullying behavior of Class VIII students to be at very low intensity both overall and based on form; 2) the tendency of cyberbullying behavior based on gender in Class VIII students is at very low intensity in each form, but there are two forms of behavior that have high intensity, namely cyberstalking and exclusion.
\end{abstract}

Keywords: Cyberbullying; Gender; Student 
PEDAGOGIA : Jurnal Ilmu Pendidikan

\section{A. PENDAHULUAN}

Penggunaan teknologi telah menjadi bagian yang tidak dapat dipisahkan dari kehidupan sehari-hari anak-anak dan remaja di Indonesia. Hadirnya teknologi berbentuk telepon genggam dengan tipe smartphone semakin memudahkan komunikasi online yang dilakukan remaja melalui media sosial. Pergeseran dari komunikasi tatap muka kekomunikasi online telah menciptakan dinamika yang unik dan berpotensi membahayakan hubungan sosial-sebuah dinamika yang baru-baru ini telah dieksplorasi dalam literatur sebagai cyberbullying dan pelecehan internet (Nixon, 2014).

Kemudahan dalam melakukan komunikasi secara online juga menjadikan remaja sebagai salah satu komunitas yang paling rentan terkena dampak negatif teknologi. Karakteristik dan sifat remaja yang sangat ingin tahu, ingin eksis, serta masih belum memiliki pertimbangan yang matang dalam beberapa hal dapat menyebabkan remaja terjerumus melakukan hal-hal negatif melalui media sosial, salah satunya dalam bentuk cyberbullying.

Cyberbullying adalah bentuk baru dari bullying yang dilakukan melalui perangkat elektronik atau media sosial. Seiring dengan semakin meningkatnya penggunaan perangkat elektronik dan media sosial oleh remaja, peristiwa cyberbullying pun cenderung mengalami peningkatan. Berdasarkan data yang diperoleh UNICEF pada tahun 2014, sebanyak 41 hingga $50 \%$ remaja di Indonesia dalam rentang usia 13 sampai 15 tahun pernah mengalami tindakan cyberbullying namun hanya sedikit sekali yang menyadarinya (UNICEF, 2014). Persentase yang tinggi dari anak-anak yang terkena cyberbullying menjadikan cyberbullying menjadi masalah kritis untuk lingkungan sekolah dan sosial mereka (Li, 2006). Teman sebaya dan jenis kelamin termasuk ke dalam lingkungan sosial remaja yang banyak berpengaruh terhadap cyberbullying.

Beberapa penelitian (Li, 2006; Smith, 2006 ; A A A , 2009 ) menyimpulkan perbedaan antara remaja laki-laki dan perempuan dalam peristiwa cyberbullying. Remaja perempuan lebih rentan terkena cyberbullying dan pelakunya sendiri adalah anak perempuan. Sementara itu, korban laki-laki, kendatipun mengalami cyberbullying namun sangat jarang memberitahu kepada orang tua kecuali jika sangat penting. Secara umum, Heiman \& Shemesh (2015) menyimpulkan bahwa perempuan cenderung menjadi korban sementara lebih cenderung menjadi pelaku cyberbullying. Lebih lanjut ditemukan bahwa remaja laki-laki lebih cenderung menyerang korbannya secara fisik sementara remaja perempuan lebih senang berbagi informasi yang menyakitkan tentang korban dengan anak lain (AASA, 2009).

Di Indonesia sendiri, relatif masih 
PEDAGOGIA : Jurnal Ilmu Pendidikan

belum banyak penelitian mengenai cyberbullying yang dikaitkan dengan jenis kelamin. Dengan demikian penelitian ini dilakukan guna melengkapi dan memberikan informasi empirik mengenai hal tersebut, terutama untuk menjawab pertanyaan : Seperti apa kecenderungan bentuk-bentuk perilaku cyberbullying peserta didik Kelas VIII SMP? Seperti apa kecenderungan bentuk-bentuk perilaku cyberbullying peserta didik Kelas VIII berdasarkan jenis kelamin?

\section{B. TINJAUAN PUSTAKA}

\section{Cyberbullying}

Cyberbullying dapat didefinisikan sebagai perilaku agresif yang dilakukan oleh satu orang maupun lebih, menggunakan media elektronik, dan diulangi berulang kali pada korban yang tidak dapat melakukan pertahanan (Smith dkk, 2006; Heiman \& Shemesh, 2015). Cyberbullying juga dapat didefinisikan sebagai luka yang diberikan secara bersungguh-sungguh dan berulang melalui media elektronik (Patchin \& Hinduja, 2006). Berdasarkan pendapat tersebut dapat disimpulkan bahwa cyberbullying merupakan tindakan kekerasan dari seseorang ataupun kelompok yang memanfaatkan sarana teknologi dalam berkomunikasi seperti chat, messaging, dan sebuah foto kepada seseorang yang dilakukan secara sengaja untuk melukai, mengancam, dan melecehkannya.
Willard (2005) menyebutkan macam-macam bentuk cyberbullying sebagai berikut.

1) Flaming (amarah): yaitu mengirimkan pesan teks yang isinya merupakan kata-kata yang penuh amarah dan frontal.

2) Harassment (gangguan): pesanpesan yang berisi gangguan yang menggunakan email, sms, maupun pesan teks di jejaring sosial dilakukan secara terus menerus.

3) Denigration (pencemaran nama baik): yaitu proses mengumbar keburukan seseorang di internet dengan maksud merusak reputasi dan nama baik orang tersebut.

4) Cyberstalking (mengikuti): mengganggu dan mencemarkan nama baik seseorang secara intens sehingga membuat ketakutan besar pada orang tersebut.

5) Impersonation (peniruan): berpurapura menjadi orang lain dan mengirimkan pesan-pesan atau status yang tidak baik.

6) Trickery (menipu): membujuk seseorang dengan tipu daya agar mendapatkan rahasia atau foto pribadi orang tersebut dengan maksud dan tujuan tertentu.

7) Outing ( menyebarkan ): menyebarkan rahasia orang lain, atau foto-foto pribadi orang lain dengan maksud dan tujuan tertentu.

8) Exclusion (mengeluarkan): secara sengaja dan kejam mengeluarkan 
PEDAGOGIA : Jurnal Ilmu Pendidikan

seseorang dari grup online.

Cyberbullying dibedakan dari tindakan bullying langsung dalam empat hal: 1) anak-anak yang menjadi korban tidak memiliki tempat untuk sembunyi, dan dapat menjadi target kapanpun dan di manapun; 2) cyberbullying dapat melibatkan audiens yang sangat luas (misalnya, melalui perputaran video klip di internet); 3) anak-anak yang melakukan cyberbullying kepada orang lain relatif dilindungi oleh kontak anonimitas elektronik, yang dapat mengamankan mereka dari hukuman atau balas dendam; serta 4) berbeda dengan tindakan bullying langsung, siswa yang melakukan cyberbullying biasanya tidak melihat langsung respon korban, dan hal itu mengubah hakikat kepuasan atau penghambatan yang biasanya disebabkan oleh bullying (AASA, 2009).

\section{Dampak Cyberbullying}

Price dan Dalgeish (dalam Haryati, 2014) mengungkapkan dampak negatif jangka pendek dari cyberbullying yaitu perasaan takut, loneliness, cemas, tidak aman, depresi, dan kelemahan akademik. Diungkapkan oleh Benran dan Li (Haryati, 2014) peserta didik yang mengalami cyberbullying melaporkan perasaan kesedihan, kecemasan, perasaan takut dan tidak dapat konsentrasi sehingga berdampak terhadap prestasinya. Hasil penelitian Nixon (2014) juga mengungkapkan remaja korban cyberbullying melaporkan peningkatan dampak depresi, kecemasan, kesepian, perilaku bunuh diri, dan gejala somatik. Sementara itu, pelaku cyberbullying lebih cenderung melaporkan peningkatan penggunaan zat terlarang, agresi, dan perilaku nakal.

Secara lebih rinci, Sciarra (2004; Banks, 1997) membagi dua dampak bullying (termasuk cyberbullying) yaitu jangka pendek dan jangka panjang. Dampak jangka pendek mencakup ketidakbahagiaan, rasa sakit dan keterhinaan, bingung, kesusahan, kehilangan harga diri, kegelisahan, ketidakamanan, dan kehilangan konsentrasi, berkontribusi terhadap rendahnya tingkat kehadiran dan rendahnya prestasi akademik. Adapun dampak jangka panjang mencakup depresi dan harga diri yang rendah, tingginya kenakalan remaja dan kejahatan orang dewasa.

\section{Perilaku Cyberbullying Remaja dan Stereotip Jenis kelamin}

Jenis kelamin merujuk pada segala sesuatu yang berhubungan dengan fisik dengan kepribadian individu, termasuk peran, tingkah laku, kecenderungan, dan atribut lain yang mendefinisikan arti menjadi seorang laki-laki atau perempuan dalam kebudayaan yang ada (Baron \& Byrne, 2004, hlm. 187).

Cyberbullying merupakan salah satu bentuk dari sikap agresif seorang individu. Hal yang telah lazim mengenai sikap agresif antara perbedaan pria dan wanita 
PEDAGOGIA : Jurnal Ilmu Pendidikan

adalah pria lebih agresif daripada wanita (Dagun, 1992, hlm. 179). Hal ini juga dapat terlihat dari tabel karakteristik stereotip jenis kelamin berikut.

Tabel 1

Perbedaan Karakteristik

Stereotip Berdasarkan Jenis Kelamin

\begin{tabular}{cc}
\hline Stereotip laki-laki & Stereotip perempuan \\
\hline $\begin{array}{c}\text { Bertindak sebagai } \\
\text { seorang pemimpin }\end{array}$ & Penuh perasaan \\
\hline Agresif & Ceria \\
\hline Ambisius & Seperti anak-anak \\
\hline Analitis & Penuh belas kasih \\
\hline Asertif & $\begin{array}{c}\text { Tidak menggunakan } \\
\text { kata-kata yang kasar }\end{array}$ \\
\hline Atletis & $\begin{array}{c}\text { Ingin menentramkan } \\
\text { perasaan yang terluka }\end{array}$ \\
\hline Kompetitif & Feminin \\
\hline Mempertahankan & Ingin disanjung \\
\hline keyakinannya & Lemah lembut
\end{tabular}

(Sumber: Baron \& Byrne, 2004)

Dalam hal tindakan cyberbullying, perbedaan jenis kelamin tidak terlalu terlihat dan terdapat sedikit perbedaan tentang jenis kelamin pada korban menurut Olweus (dalam Slonje \& Smith, 2008). Berbeda dengan bullying tradisional, anak laki-laki cenderung lebih agresif secara fisik dan karenanya anak laki-laki juga mungkin lebih menerima bullying dibandingkan anak perempuan (AASA, 2009). Lebih lanjut ditemukan hasil bahwa anak laki-laki lebih sering terlibat sebagai pelaku dan korban bullying dibandingkan anak perempuan. Sementara itu, anak perempuan cenderung membully anak perempuan lain secara tidak langsung melalui kelompok teman sebaya. Anak perempuan juga dilaporkan lebih sering mengalami bullying secara seksual dibandingkan dengan anak laki-laki (AASA, 2009).

\section{Pengukuran Kecenderungan Perilaku Cyberbullying \\ Willard (2005) memaparkan} bentuk-bentuk mengenai perilaku cyberbullying dengan tujuh bentuk, yaitu: flaming, harassment, cyberstalking, denigration, impersonation, outing and trickery, dan exclusion. Tujuh bentuk tersebut menjadi acuan alat ukur atau instrumen yang digunakan dalam mengukur perilaku cyberbullying. Willard (2005) juga menyusun instrumen tersebut dalam bukunya dan instrumen tersebut bernama Students Assessment Survey (SAS). Instrumen tersebut merupakan alat ukur yang digunakan dalam mencari informasi dari peserta didik mengenai cyberbullying dan cyberthreaths. Hasil pengukuran tersebut dimaksudkan untuk pihak sekolah agar dapat memberikan solusi yang tepat untuk peserta didik di sekolahnya. Alat ukur tersebut memiliki 30 butir pertanyaan dengan beberapa pertanyaan yang memiliki anak pertanyaan di dalamnya.

\section{METODE PENELITIAN}

Pendekatan penelitian yang digunakan adalah kuantitatif dengan 
PEDAGOGIA : Jurnal Ilmu Pendidikan

metode deskriptif dan desain penelitian survei. Populasi penelitian adalah peserta didik Kelas VII di salah satu SMPN di Bandung Tahun Ajaran 20017/2018. Adapun sampel penelitian adalah peserta didik Kelas VIII SMP yang berjumlah 320 orang, dengan rincian 148 orang laki-laki dan 172 orang perempuan.

Pengumpulan data menggunakan instrumen berupa angket tertutup. Instrumen tersebut merupakan pengembangan dari penelitian sebelumnya (Alfriyanti, 2016) dengan alat ukur cyberbullying yang telah melalui proses judgement expert oleh dua orang ahli. Instrumen tersebut merujuk pada teori Willard (2005). Angket tertutup yang berbentuk kuesioner untuk mengungkap perilaku cyberbullying menggunakan Skala Likert.

\section{HASIL DAN PEMBAHASAN}

Gambaran umum tingkat perilaku cyberbullying peserta didik Kelas VIII Tahun Ajaran 2017/2018 dapat dilihat pada Tabel 2 .

\section{Tabel 2}

Kecenderungan Umum Intensitas Perilaku

Cyberbullying Peserta Didik Kelas VIII SMP

Negeri 7 Bandung 2017/2018

\begin{tabular}{cc}
\hline Jumlah Responden & 320 \\
\hline Rata-rata & 7,75 \\
\hline Standar Deviasi & 5,99 \\
\hline
\end{tabular}

Berdasarkan Tabel 2, diketahui bahwa peserta didik lebih banyak berada pada intensitas rendah sekali dalam melakukan tindakan cyberbullying kepada teman sebayanya.

Selanjutnya, berdasarkan data distribusi intensitas, kecenderungan perilaku cyberbullying dapat disajikan dalam bentuk Tabel 3 seperti berikut.

Tabel 3

Distribusi Kecenderungan Intensitas Perilaku

Cyberbullying Peserta Didik Kelas VIII SMP

\begin{tabular}{lccc}
\hline Intensitas & $\begin{array}{c}\text { Rentang } \\
\text { Skor }\end{array}$ & Frekuensi & Persentase \\
& $>64-80$ & - & - \\
Tinggi & & & \\
Sekali & & - & - \\
\hline Tinggi & $>48-64$ & 3 & 0,94 \\
\hline Sedang & $>32-48$ & 34 & 7,5 \\
\hline Rendah & $>16-32$ & 24 & 91,56 \\
\hline Rendah & $0-16$ & 293 & \\
sekali & & &
\end{tabular}

Berdasarkan Tabel 3, tampak bahwa mayoritas tingkat perilaku cyberbullying peserta didik berada pada intensitas yang rendah sekali, sedangkan sisanya berada pada intensitas rendah dan sedang dengan selisih jumlah yang sedikit. Hasil menunjukkan dari 320 orang peserta didik, terdapat sebanyak 3 peserta didik atau 0,94\% berada pada intensitas sedang, sebanyak 24 peserta didik atau 7,5\% berada pada intensitas rendah, sedangkan sebanyak 293 peserta didik atau 91,56\% berada pada intensitas rendah sekali. Selanjutnya, sebesar $15,3 \%$ peserta didik lainnya berada pada kategori rendah.

Berdasarkan hasil temuan penelitian, secara keseluruhan dapat disimpulkan bahwa kecenderungan 
PEDAGOGIA : Jurnal Ilmu Pendidikan

perilaku cyberbullying peserta didik Kelas VIII SMPN Tahun Ajaran 2017/2018 berada pada kategori sedang dengan ratarata pencapaian skor sebesar -2,44. Hasil rata-rata tersebut menunjukkan sebagian besar peserta didik memiliki intensitas yang cenderung rendah namun cukup tinggi di antara keseluruhan populasi.

Kecenderungan perilaku cyberbullying peserta didik Kelas VIII pada umumnya berada pada intensitas yang rendah sekali, seperti yang terlihat pada tabel di bawah.

\section{Tabel 4}

Kecenderungan Intensitas Bentuk Perilaku

Cyberbullying Peserta Didik Kelas VIII

\begin{tabular}{cccccc}
\hline Bentuk & Ket & $\mathbf{T}$ & $\mathbf{S}$ & $\mathbf{R}$ & $\mathbf{R S}$ \\
\hline \multirow{2}{*}{ Flaming } & $\mathrm{F}$ & 4 & 8 & 48 & 260 \\
\cline { 2 - 6 } & $\mathrm{P}$ & 1,25 & 2,5 & 15 & 81,25 \\
\hline \multirow{2}{*}{ Harassment } & $\mathrm{F}$ & 1 & 1 & 15 & 303 \\
\cline { 2 - 6 } & $\mathrm{P}$ & 0,31 & 0,31 & 4,68 & 94,68 \\
\hline \multirow{2}{*}{ Denigration } & $\mathrm{F}$ & - & 2 & 30 & 288 \\
\cline { 2 - 6 } & $\mathrm{P}$ & - & 0,62 & 9,38 & 90 \\
\hline \multirow{2}{*}{ Cyberstalking } & $\mathrm{F}$ & 36 & 40 & 141 & 103 \\
\cline { 2 - 6 } & $\mathrm{P}$ & 11,3 & 12,5 & 44 & 32,2 \\
\hline \multirow{2}{*}{ Impersonation } & $\mathrm{F}$ & 4 & 9 & 49 & 258 \\
\cline { 2 - 6 } & $\mathrm{P}$ & 1,25 & 2,81 & 15,31 & 80,63 \\
\hline \multirow{2}{*}{ Trickery } & $\mathrm{F}$ & 1 & 2 & 37 & 280 \\
\cline { 2 - 6 } & $\mathrm{P}$ & 0,3 & 0,63 & 11,57 & 87,5 \\
\hline \multirow{2}{*}{ Outing } & $\mathrm{F}$ & 2 & 1 & 27 & 290 \\
\cline { 2 - 6 } & $\mathrm{P}$ & 0,63 & 0,3 & 8,44 & 90,63 \\
\hline \multirow{2}{*}{ Exclusion } & $\mathrm{F}$ & 9 & 8 & 88 & 215 \\
\cline { 2 - 6 } & $\mathrm{P}$ & 2,8 & 2,5 & 27,5 & 67,2 \\
& $\mathrm{k} a n$ & 19 & 4 & 1 & \\
\hline
\end{tabular}

Berdasarkan Tabel 4 tampak bahwa peserta didik melakukan beberapa tindakan cyberbullying dalam bentukbentuk yang sesuai dengan teori Willard (2005) yaitu flaming (amarah), harassment (melecehkan), cyberstalking (mengikuti atau mengancam), denigration (pencemaran nama baik), impersonation (peniruan), outing and trickery (menyebarkan rahasia pribadi dengan cara menipu), serta exclusion (mengeluarkan).

\section{Kecenderungan Umum Tingkat Perilaku Cyberbullying Peserta Didik berdasarkan Jenis Kelamin}

Gambaran umum intensitas perilaku cyberbullying peserta didik berdasarkan jenis kelamin laki-laki dan perempuan dapat dilihat pada Tabel 5.

Tabel 5

Kecenderungan Umum Intensitas Perilaku

Cyberbullying Peserta Didik Kelas VIII berdasarkan Jenis Kelamin

\begin{tabular}{ccc}
\hline Keterangan & $\begin{array}{c}\text { Laki- } \\
\text { laki }\end{array}$ & Perempuan \\
\hline $\begin{array}{c}\text { Jumlah } \\
\text { Responden }\end{array}$ & 148 & 172 \\
\hline Rata-rata & 10,88 & 7,15 \\
\hline $\begin{array}{c}\text { Standar } \\
\text { Deviasi }\end{array}$ & 8,40 & 5,42 \\
\hline
\end{tabular}

Berdasarkan Tabel 5, dapat diketahui gambaran umum perilaku cyberbullying pada 148 orang peserta didik laki-laki, menunjukkan rata-rata 10,88 dan standar deviasinya $(S D)$ yaitu 8,40 . Hal ini membuktikan peserta didik lebih banyak berada pada intensitas rendah sekali dalam melakukan tindakan cyberbullying.

Peserta didik perempuan dengan 
PEDAGOGIA : Jurnal Ilmu Pendidikan

jumlah 172 orang menunjukkan rata-rata 7,15 dengan standar deviasi $(S D)$ sebesar 5,42 . Hal ini menunjukkan laki-laki cenderung lebih tinggi intensitasnya dalam melakukan tindakan cyberbullying daripada perempuan, namun keduanya sama-sama berada pada intensitas yang rendah sekali.

Berdasarkan intensitas cyberbullying yang dikelompokkan sebelumnya, gambaran umum perilaku cyberbullying peserta didik berdasarkan jenis kelamin laki-laki dan perempuan disajikan dalam bentuk Tabel 6 sebagai berikut.

\section{Tabel 6}

Perbedaan Tingkat Perilaku Cyberbullying

Peserta Didik Kelas VIII Berdasakan Jenis Kelamin

\begin{tabular}{|c|c|c|c|c|c|c|}
\hline Bentuk & JK & Ket & $\mathbf{T}$ & $\mathbf{S}$ & $\mathbf{R}$ & RS \\
\hline \multirow[t]{4}{*}{ Flaming } & \multirow{2}{*}{$\mathrm{L}$} & $\mathrm{F}$ & 2 & 7 & 28 & 111 \\
\hline & & $\mathrm{P}$ & 1,3 & 4,7 & 19 & 75 \\
\hline & \multirow{2}{*}{$\mathrm{P}$} & $\mathrm{F}$ & 2 & 1 & 20 & 144 \\
\hline & & $\mathrm{P}$ & 1,2 & 0,6 & 11,5 & 83,7 \\
\hline \multirow{4}{*}{$\begin{array}{l}\text { Harass } \\
\text { ment }\end{array}$} & \multirow{2}{*}{$\mathrm{L}$} & $\mathrm{F}$ & 1 & 1 & 11 & 135 \\
\hline & & $\mathrm{P}$ & 0,7 & 0,7 & 7,4 & 91,2 \\
\hline & \multirow{2}{*}{$\mathrm{P}$} & $\mathrm{F}$ & - & - & 4 & 168 \\
\hline & & $\mathrm{P}$ & - & - & 2,3 & 97,7 \\
\hline \multirow{4}{*}{$\begin{array}{l}\text { Denigrati } \\
- \text { on }\end{array}$} & \multirow{2}{*}{$\mathrm{L}$} & $\mathrm{F}$ & - & 1 & 7 & 140 \\
\hline & & $P$ & - & 0,7 & 4,7 & 94,6 \\
\hline & \multirow{2}{*}{$\mathrm{P}$} & $\mathrm{F}$ & - & 1 & 23 & 148 \\
\hline & & $\mathrm{P}$ & - & 0,6 & 13,4 & 86 \\
\hline \multirow{4}{*}{$\begin{array}{l}\text { Cyber- } \\
\text { staking }\end{array}$} & \multirow{2}{*}{$\mathrm{L}$} & $\mathrm{F}$ & 15 & 15 & 61 & 57 \\
\hline & & $\mathrm{P}$ & 10,2 & 10,2 & 41,1 & 38,5 \\
\hline & \multirow{2}{*}{$\mathrm{P}$} & $\mathrm{F}$ & 21 & 25 & 80 & 46 \\
\hline & & $\mathrm{P}$ & 12,2 & 14,6 & 46,5 & 26,7 \\
\hline \multirow{4}{*}{$\begin{array}{l}\text { Imperso- } \\
\text { nation }\end{array}$} & \multirow{2}{*}{$\mathrm{L}$} & $\mathrm{F}$ & 2 & 6 & 22 & 118 \\
\hline & & $\mathrm{P}$ & 1,3 & 4 & 14,9 & 79,8 \\
\hline & \multirow{2}{*}{$\mathrm{P}$} & $\mathrm{F}$ & 2 & 3 & 27 & 140 \\
\hline & & $\mathrm{P}$ & 1,2 & 1,7 & 15,7 & 81,4 \\
\hline
\end{tabular}

\begin{tabular}{|c|c|c|c|c|c|c|}
\hline \multirow[t]{4}{*}{ Trickery } & \multirow{2}{*}{$\mathrm{L}$} & $\mathrm{F}$ & 1 & - & 23 & 124 \\
\hline & & $P$ & 0,7 & - & 15,5 & 83,8 \\
\hline & \multirow{2}{*}{$P$} & $\mathrm{~F}$ & - & 2 & 14 & 156 \\
\hline & & $\mathrm{P}$ & - & 1,2 & 8,1 & 90,7 \\
\hline \multirow[t]{4}{*}{ Outing } & \multirow{2}{*}{$\mathrm{L}$} & $\mathrm{F}$ & - & 1 & 10 & 137 \\
\hline & & $\mathrm{P}$ & - & 0,7 & 6,7 & 92,6 \\
\hline & \multirow{2}{*}{$\mathrm{P}$} & $\mathrm{F}$ & 2 & - & 17 & 153 \\
\hline & & $\mathrm{P}$ & 1,2 & - & 9,9 & 88,9 \\
\hline \multirow[t]{4}{*}{ Exclusion } & \multirow{2}{*}{$\mathrm{L}$} & $\mathrm{F}$ & 5 & 4 & 44 & 95 \\
\hline & & $\mathrm{P}$ & 3,4 & 2,7 & 29,7 & 64,2 \\
\hline & \multirow{2}{*}{$\mathrm{P}$} & $\mathrm{F}$ & 4 & 4 & 44 & 120 \\
\hline & & $\mathrm{P}$ & 2,3 & 2,3 & 25,6 & 69,8 \\
\hline
\end{tabular}

Temuan penelitian menunjukkan tidak terdapat peserta didik pada intesitas tinggi sekali, dan sebanyak $91,56 \%$ atau 293 peserta didik berada pada intensitas rendah sekali dalam perilaku cyberbullying.

Peserta didik dengan intensitas tinggi dapat diartikan bahwa peserta didik tersebut cenderung sering terlibat sebagai pelaku dan melakukan tindakan cyberbullying kepada orang lain ataupun teman sebayanya. Peserta didik tersebut memiliki intensitas yang cukup tinggi dalam melakukan tindakan cyberbullying daripada peserta didik lain yang berada pada intensitas sedang, rendah, atau rendah sekali. Peserta didik tersebut dapat melakukan semua atau sebagian besar dari indikator yang ada pada bentuk cyberbullying dimulai dari flaming hingga exclusion. Adapun peserta didik dengan intensitas sedang berarti peserta didik tersebut pernah atau beberapa kali melakukan tindakan cyberbullying baik kepada orang lain maupun teman sebayanya di sekolah. Intensitas peserta 
PEDAGOGIA : Jurnal Ilmu Pendidikan

didik tersebut dalam melakukan tindakan cyberbullying tersebut tidak sering dan hanya terlibat pada beberapa indikator dalam bentuk cyberbullying yang ada.

Peserta didik dengan intensitas rendah dapat diartikan bahwa peserta didik tersebut memiliki intensitas yang rendah, jarang, atau bahkan tidak terlibat dalam melakukan tindakan cyberbullying kepada orang lain ataupun teman sebayanya. Peserta didik tersebut tidak melakukan tindakan pada semua bentuk cyberbullying atau hanya pernah melakukan beberapa kali tindakan pada sebagian kecil bentuk cyberbullying yang ada.

Remaja yang berada pada intensitas tersebut cenderung memiliki kemampuan komunikasi, relasi yang baik dengan kawan sebaya, dan juga memiliki penyesuaian diri yang baik. Hal tersebut menjadi salah satu alasan seseorang dapat terhindar dari perilaku cyberbullying dengan kawan sebaya (Sari dkk, 2014).

Selain itu menurut keterangan responden sendiri, rendahnya keterlibatan mereka dalam cyberbullying adalah karena pemahaman mengenai bahaya dan konsekuensi hukuman dalam berkata kasar, menghina, dan mengejek di media sosial. Hal ini dapat menjelaskan alasan sebagian responden memiliki kontrol diri yang baik dalam penggunaan media sosial.

Remaja yang memiliki kecenderungan perilaku cyberbullying memiliki beberapa alasan yang dapat menimbulkan hal tersebut terjadi di lingkungannya. Perilaku cyberbullying disebabkan oleh hal-hal seperti semakin meningkatkan interaksi antara manusia dengan teknologi; era multi-tasking; perbedaan gaya komunikasi antara orang dewasa dengan remaja; kegagalan orang dewasa dalam menanamkan nilai-nilai empati kepada anaknya; serta orang dewasa, sekolah, dan masyarakat gagal memelihara sikap kasih sayang dan bertanggung jawab kepada anak. Perbedaan gaya komunikasi antara orang tua dengan remaja, membuat remaja lebih percaya dan terbuka kepada kawan sebayanya (Sari dkk, 2014).

Selain faktor internal dan eksternal tersebut, terdapat pula faktor lain yang menyebabkan adanya perilaku cyberbullying pada usia remaja yaitu usia yang terlalu dini untuk memiliki sebuah alat komunikasi yang canggih sehingga peserta didik dinilai belum memahami etika berkomunikasi yang baik di dunia maya serta aturan hukum yang ada (Pandie \& Wesmann, 2016). Dengan demikian, peran serta orang tua sangat penting dalam memahami dampak dan penyebab cyberbullying.

Alasan utama remaja melakukan cyberbullying adalah untuk bercanda, ingin melakukan balas dendam, atau karena mereka marah atau membenci korban. Ketiga jawaban ini nampaknya relevan satu sama lain. Merujuk pada hasil yang terdapat dalam penelitian, tampak bahwa pada awalnya remaja membully 
temannya dengan maksud untuk bercanda. Namun, korban menganggap hal yang dilakukan pelaku itu bukan sebagai candaan. Karenanya hal tersebut membuat mereka malu dan sakit hati, yang mendorong mereka membalas dendam terhadap pelaku. Sebagai hasilnya, mereka menjadi saling membully (Sartana \&Afriyeni, 2017).

Apabila ditelaah, perilaku peserta didik laki-laki dan peserta didik perempuan pada saat usia remaja awal cenderung senang dalam bergaul dan mencoba dalam berbagai hal. Hal ini dapat menjadi alasan bahwa perilaku cyberbullying terjadi karena hubungan pertemanan yang sangat dekat, pernah dekat, atau karena konflik. Perilaku yang ditunjukkan sesuai dengan peran jenis kelaminnya tidak mendominasi dalam hal cyberbullying karena kebiasaan, interaksi, dan aktivitas yang cenderung sama di antara keduanya.

Selain itu, pada penelitian yang dilakukan oleh Budiarti (2016) dijelaskan bahwa persepsi cyberbullying yang ditemukan nampak masih dianggap tidak serius atau bercanda. Beberapa indikator perilaku cyberbullying cenderung tidak dianggap sebagai perilaku cyberbullying, namun lebih kepada bercanda atau bahkan mereka tidak menyadari bahwa itu termasuk perilaku cyberbullying. Hal tersebut dikarenakan pelaku merasa korban tidak marah atau menunjukkan emosi yang negatif atas tindakan tersebut. Namun, hal tersebut kemudian menjadi bemasalah karena mungkin saja korban merasa takut untuk menunjukkan emosinya. Maka dari itu, cyberbullying cenderung terjadi di antara mereka tanpa disadari dampak yang mungkin terjadi pada objek candaan atau humor tersebut.

Interaksi, pergaulan, dan persahabatan terjalin begitu kuat dengan berbagai alasan yang diinginkan oleh peserta didik. Pencitraan yang baik di mata orang lain, gaul, terkenal, dan mempunyai banyak penggemar atau dikagumi orang lain adalah beberapa alasan yang menjadikan seorang peserta didik menjadi aktif dalam sosial media. Jenis kelamin pada akhirnya tidak terlalu menjadi acuan, karena keduanya sedang berada dalam masa yang senang bergaul dan mencari identitas diri.

Menurut hasil penelitian, umumnya peserta didik Kelas VIII berada pada intensitas yang rendah sekali dalam segala bentuk perilaku cyberbullying. Namun terindikasi beberapa peserta didik melakukan dua bentuk cyberbullying yaitu cyberstalking dan exclusion, baik pada laki-laki maupun perempuan. Hal tersebut terjadi karena pada masa remaja mereka memiliki rasa ingin tahu yang sangat tinggi namun di sisi lain mereka pun belum memiliki pertimbangan yang matang dalam menentukan keputusan (Yusuf, 2015).

Diharapkan seiring dengan semakin matangnya proses perkembangan jati diri yang disertai dengan pemberian pembekalan pengetahuan untuk peserta didik mengenai bentuk dan dampak 
PEDAGOGIA : Jurnal Ilmu Pendidikan

cyberbullying dapat membantu mengurangi jumlah aktivitas dan perilaku cyberbullying yang terjadi.

\section{E. KESIMPULAN}

Berdasarkan hasil temuan penelitian dapat disimpulkan bahwa kecenderungan perilaku cyberbullying pada peserta didik Kelas VIII berada pada intensitas rendah sekali, baik secara keseluruhan maupun berdasarkan bentuk. Artinya, peserta didik cenderung tidak melakukan dan terlibat pada tindakan cybebullying dengan teman sebayanya.

Kecenderungan intensitas perilaku cyberbullying berdasarkan jenis kelamin peserta didik kelas VIII berada pada intensitas rendah sekali pada setiap bentuk yang ada seperti flaming, harassment, cyberstalking, denigration, impersonation, outing and trickery, serta exclusion. Kendatipun demikian terdapat dua bentuk cyberbullying yang cukup tinggi intensitasnya yaitu cyberstalking (mengikuti/menguntit) dan exclusion (mengeluarkan) baik pada remaja lakilaki maupun perempuan.

Penelitian yang dilaksanakan pada peserta didik Kelas VIII SMP menunjukkan sebagian besar peserta didik tidak pernah melakukan tindakan cyberbullying. Kendatipun demikian sebagian besar peserta didik belum memahami etika berkomunikasi dan memiliki relasi yang baik dengan teman sebayanya di dunia maya maupun media sosial. Dengan demikian Guru mata pelajaran disarankan agar dapat membantu meningkatkan kemampuan-kemampuan peserta didik yang berkaitan dengan bekerja sama dengan teman sebaya dan komunikasi yang baik agar dapat membantu peserta didik menjadi pribadi yang lebih baik.

Di samping itu, Guru Bimbingan dan Konseling/Konselor diharapkan mampu mengidentifikasi adanya pelaku maupun korban cyberbullying untuk diberikan tindak lanjut baik melalui bimbingan ataupun konseling. Guru Bimbingan dan Konseling/Konselor disarankan untuk memantau cara berkomunikasi peserta didik sehari-hari di lingkungan sekolah karena hal tersebut sangat mungkin berpengaruh terhadap cara mereka berkomunikasi di dunia maya.

\section{DAFTAR PUSTAKA}

Alfriyanti, Ayu. (2016). Hubungan antara Regulasi Emosi dan Perilaku Cyberbullying. (Skripsi). Fakultas Ilmu Pendidikan Universitas Pendidikan Indonesia, Bandung.

AASA (American Association of School Administrator). (2009). Bullying at School and Online. California: Education.com Holding, Inc.

Banks, R. (1997). Bullying in School. (Online). Diakses pada 31 Mei 2018. http://www.eric.ed/educationalresear chjournal article/downloads.pdf.

Baron, Robert A. \& Byrne, Donn. (2004). 
PEDAGOGIA : Jurnal Ilmu Pendidikan

Psikologi Sosial. Jakarta: Erlangga.

Budiarti, Arsa Ilmi. (2016). Pengaruh Interaksi dalam Peer Group terhadap Perilaku Cyberbullying Siswa. Jurnal Pemikiran Sosiologi 3(1), 1-15.

Dagun M. Save. (1992). Maskulin dan Feminin. Jakarta: Rineka Cipta.

Haryati. (2014). Cyberbullying Sisi Lain Dampak Negatif Internet. Mediakom, (11), 46-63.

Hinduja, Sameer \& Patchin, Justin W. (2006). Bullies Move Beyond The Schoolyard A Preliminary Look at Cyberbullying. Youth Violence and Juvenile Justice, (4)2, 148-169. doi: $10.1177 / 1541204006286288$.

Li, Qing. (2006). Cyberbullying in Schools: A Research of Gender Differences. School Psychology International, 27(2), 157-170. doi: 10.1177/0143034306064547.

Maya, Nur. (2015). Fenomena Cyberbullying di Kalangan Pelajar. Jurnal Ilmu Sosial dan Ilmu Politik, (4) 3, 443-450.

Nixon, Charisse L. (2014). Current Perspectives: The Impact of Cyberbullying on Adolescent Health. Adolesc Health Med Ther. $2014 ; 5$ : $143-158$. doi:10.2147/AHMT.S36456.

Pandie, Mira M \& Weismann, Ivan. (2016). Pengaruh Cyberbullying di Media Sosial terhadap Perilaku Reaktif Sebagai Pelaku Maupun Sebagai Korban Cyberbullying pada Siswa Kristen SMP Nasional Makassar. Jurnal Jaffray, 14(1). 4362. doi: 10.252781.188.

Sari, J. F., Karsih, K., \& Tjalla, A. (2014). Hubungan antara Penyesuaian Diri dengan Kecenderungan Perilaku Cyber Bullying pada Siswa Kelas Viii Smp Labschool Jakarta Tahun Ajaran 2013-2014. Insight: Jurnal Bimbingan dan Konseling, 3(1), 70-76.

Sartana \& Afriyeni, Nelia. (2017). Perilaku Perundungan Maya (Cyberbullying) pada Remaja Awal. Jurnal Psikologi Insight (1) $1, \quad 25-41$. doi:10.5281/zenodo.576972.

Sciarra, D.T. (2004). School Counseling: Foundation and Contemporary Issues. Australia: Brooks/Cole.

Slonje, R. \& Smith, P.K. (2008). Cyberbullying: Another Main Type of Bullying? Scandinavian Journal of Psychology. 49, 147-154. doi: $10.1111 / \mathrm{j} .1467$ 9450.2007.00611.x.

Smith, Peter K. et. al. (2006). An investigation into cyberbullying, its forms, awareness, and impact, and the relationship between age and gender in cyberbullying. [Online]. Diakses pada 3 Juni 2016 https://static.lgfl.net/LgflNet/downlo ads/online-safety/LGfL-OS-ResearchArchive-2006-GoldsmithsCyberbullying.pdf.

Smith, Peter K. et.al. (2007). 
PEDAGOGIA : Jurnal Ilmu Pendidikan

Cyberbullying: Its Nature and Impact in Secondary Schools. Journal of Child Psychology and Psychiatry (49)4, 376-38. d o i : $10.1111 /$ j. 1469 7610.2007.01846.x.

UNICEF. (2014). Digital Citizenship Safety among Children and Adolescent in Indonesia. (Online). Diakses pada 7 Desember 2017. http://www.unicef.org/indonesia.

Willard, Nancy. (2005). Cyberbullying and Cyberthreats. Washington: U.S Department of Education.

Willard, Nancy. (2007). Student Needs Assessment Survey. [Online] Diakses pada 7 Desember 2017 http://preventcyberbullies.weebly.co m/uploads/1/0/6/7/10674596/studs urvey.pdf.

Yusuf, Syamsu. (2015). Psikologi Perkembangan Anak dan Remaja. Bandung: PT Remaja Rosdakarya. 